\title{
Facilitation of the introduced green alga Caulerpa racemosa by resident algal turfs: experimental evaluation of underlying mechanisms
}

\author{
F. Bulleri* ${ }^{*}$ L. Benedetti-Cecchi \\ Dipartimento di Biologia, Università di Pisa, Via A. Volta 6, 56126 Pisa, Italy
}

\begin{abstract}
There is convincing evidence showing that resistance to invasion greatly varies among recipient assemblages. We assessed whether variation in the performance of the introduced macroalga Caulerpa racemosa between algal turfs and surfaces dominated by encrusting corallines (barrens) arises from their physical or biological properties, by comparing the invasion success of this alga between natural assemblages and their mimics. Furthermore, to establish whether greater retention of sediments by algal turfs can favour C. racemosa, sediment deposition in barrens was raised to levels matching those recorded in turfs. The effects of herbivores on patterns of distribution of $C$. racemosa between habitats were evaluated by removing urchins from some experimental patches. The performance of C. racemosa was greater in turfs than in barrens, regardless of the type of substratum (natural or artificial), suggesting that positive effects of turfs on C. racemosa are physical (e.g. entrapment of fragments of the alga and/or enhancing the anchoring of stolons). Removing urchins or enhancing the deposition of sediments in barrens had no effect on C. racemosa. Our results show that the complexity of biogenic substrata is key to determining the spread of this invader and that facilitation of exotic species by natives could enhance ecosystem invasibility. This study has important implications for the management of C. racemosa, as turfs are progressively replacing canopy-forming species along urbanised coasts. Also, it suggests that current invasion theories based on the assumption that interactions between native and exotic species are exclusively negative may be inadequate to predict future invasion scenarios.
\end{abstract}

KEY WORDS: Biological invasions $\cdot$ Benthic assemblages $\cdot$ Rocky reefs $\cdot$ Sedimentation $\cdot$ Facilitation $\cdot$ Turf-forming algae $\cdot$ Barren habitats $\cdot$ Caulerpa racemosa

\section{INTRODUCTION}

The introduction of non-indigenous species can alter the structure and functioning of natural ecosystems, with potential repercussions on their ability to provide goods and services to humans (Pimentel et al. 2000). A number of studies have assessed the effects of introduced species on native assemblages, at different levels of organisation (Simberloff \& Von Holle 1999, Grosholz 2002). Other studies have attempted to shed some light on the mechanisms regulating invasion success (Mack et al. 2000, Pimentel et al. 2000). There is, in fact, convincing evidence that resistance to invasion varies greatly among recipient assemblages (Levine \& D'Antonio 1999, Lonsdale 1999, Kennedy et al. 2002, Arenas et al. 2006).

A common paradigm, the biotic resistance hypothesis, postulates that species diversity can provide a barrier against invaders (Elton 1958, Levine \& D'Antonio 1999, Kennedy et al. 2002), as a more complete use of resources at higher levels of native diversity would reduce their availability for invading species (Loreau 2000, Fargione \& Tilman 2005). Predictions from this model are, however, grounded on the assumption that the effects of native species on invaders are exclusively or predominantly negative, at odds with convincing 
experimental evidence suggesting that positive species interactions are key determinants of ecosystem structure and functioning (Bertness \& Callaway 1994, Callaway 1995, Bruno et al. 2003). To date, positive effects of native species on the establishment of invaders have been largely overlooked in marine environments (but see Ceccherelli et al. 2002, Levin et al. 2002, Bulleri \& Airoldi 2005, Stachowicz \& Byrnes 2006, Bulleri et al. 2008).

The introduced green alga Caulerpa racemosa (Forsskål) J. Agardh has been indicated as a driver of change in patterns of abundance and distribution of resident assemblages on rocky (Piazzi et al. 2001) and sandy (Argyrou et al. 1999) bottoms of the western Mediterranean Sea. Understanding the factors that regulate the establishment and spread of this species is, therefore, crucial to predicting future pathways of invasion and susceptible locales.

Ceccherelli et al. (2002) have experimentally shown that the ability of Caulerpa racemosa to spread and grow was greater in algal turfs than in the presence of simpler algal forms such as encrusting corallines. No study has, however, attempted to identify the nature of the mechanisms underlying the facilitation of $C$. racemosa by algal turfs, in respect to substrata dominated by encrusting forms. This study aims at filling this gap, by testing hypotheses derived from alternative models able to explain variations in the performance of $C$. racemosa between algal assemblages.

As also suggested by Ceccherelli et al. (2002), the effects of algal turfs on Caulerpa racemosa may arise from its physical properties; due to the tight packing of species and to the dense network of ramifications (Airoldi et al. 1995), algal turfs may provide a complex 3-dimensional substratum that favours the entrapment of fragments of the alga and the anchoring of its stolons. It might therefore be predicted that differences in the invasion success of $C$. racemosa between algal turfs (greater complexity) and barren habitats (surfaces monopolised by encrusting corallines characterised by a smaller complexity) would emerge either in natural assemblages or in mimics (artificial substrata with complexities comparable to those of the natural counterparts). In contrast, if variation in the effects on C. racemosa between algal assemblages stems from their biological features (e.g. exudation of chemicals, monopolisation of nutrients, palatability to grazers), differences should be found between natural algal assemblages but not between mimics.

Alternatively, the greater ability of algal turfs to trap sediments in comparison to barren grounds (Airoldi et al.1996) may underlie the variation in the performance of Caulerpa racemosa between these 2 habitats. $C$. racemosa is highly resistant to sedimentation (Piazzi et al. 2007) and, indeed, experimental enhancement of sediment deposition had slightly positive effects on this species when growing within a complex algal assemblage including encrusting, turf-forming and erect species (Piazzi et al. 2005). A layer of sediments may favour the spread of C. racemosa into barren habitats through the same mechanisms proposed for algal turfs, i.e. entrapping fragments and preventing dragging by hydrodynamic forces. Also, beneath sediments, low irradiance conditions may foster the growth of rhizoids (as shown for $C$. prolifera by Friedlander et al. 2006), allowing the alga to rapidly gain a firm hold to the underlying rocky substratum. Being a rhizophytic alga, C. racemosa may also be favoured by an eventual enhancement in nutrients generated by the accumulation of sediments (Larned 1998). Under these premises, it can be predicted that raising the retention of sediments in barren habitats (either natural or artificial) to levels found in algal turfs would enhance the colonisation by $C$. racemosa and cancel out differences between these habitats.

Finally, algal turfs may favour Caulerpa racemosa by reducing the impact of grazers in comparison to barren habitats. The urchins Paracentrotus lividus and Arbacia lixula are generally found on barren surfaces they produce in the surroundings of their shelters, but rarely in algal turfs, probably because of their limited ability to adhere firmly to this substratum (BenedettiCecchi et al. 1998). Grazing pressure and foraging efficiency are, therefore, likely to be greater on surfaces dominated by encrusting corallines close to shelters than on algal turfs along the external margins of browsed patches. This could result in a greater success of C. racemosa in algal turfs. In this case, differences in the performance of C. racemosa between algal assemblages would vanish or lessen following the removal of urchins.

We tested these hypotheses simultaneously, by comparing the spread and performance of Caulerpa racemosa among different combinations of habitat (algal turfs versus barrens at enhanced regime of sediment deposition versus barrens at natural regime of sediment deposition), types of substratum (natural versus artificial) and grazing regimes (urchins present versus urchins removed).

\section{MATERIALS AND METHODS}

Study system. This study was done along an exposed sandstone rocky shore about $5 \mathrm{~km}$ south of Livorno (Calafuria, $43^{\circ} 30^{\prime} \mathrm{N}, 10^{\circ} 20^{\prime} \mathrm{E}$ ) on the northwest coast of Italy, between May and August 2006. Shallow rocky reefs, at depths varying from 4 to $6 \mathrm{~m}$, are dominated by turf-forming species, but grazing by the sea urchins Arbacia lixula and Paracentrotus lividus pro- 
duces patches dominated by encrusting corallines (Benedetti-Cecchi et al. 1998, Bulleri et al. 1999). Algal turfs are composed by small (less than $5 \mathrm{~cm}$ in height) tightly-packed species, with filamentous forms dominating (Sphacelaria spp., Ceramium sp. and, to a lesser extent, Womersleyella setacea). Other algal forms, such as geniculated corallines (Amphiroa rigida, Corallina elongata and Jania rubens), coarsely branched (Gastroclonium clavatum, Laurencia obtusa and Chondria sp.) and foliose algae (Padina pavonica, Dyctiota dichotoma, Taonia atomaria and Acetabularia acetabulum) are, however, present and can be locally abundant. Barren patches are monopolised by encrusting corallines (mostly Neogoniolithon brassica-florida), but other encrusting forms, such as Peyssonnelia spp. and Pseudolithoderma sp. can be present. Sessile invertebrates are represented by the tubiculous gastropod Vermetus triqueter and by the barnacle Balanus perforatus.

The introduced green alga Caulerpa racemosa var. cylindracea has become a common component of benthic assemblages on these rocky bottoms (Piazzi et al. 1994). Rapid vegetative propagation of prostrate stolons (up to $2 \mathrm{~cm} \mathrm{~d}^{-1}$; Piazzi \& Cinelli 1999) and dispersal through fragments (Ceccherelli \& Piazzi 2001) have been identified as the main mechanisms of spreading. The reproductive strategy of C. racemosa, along with the capability of colonising both rocky and soft bottoms, has contributed to its remarkable invasiveness (Piazzi et al. 2005). In the Mediterranean Sea, this alga alternates a period of vegetative growth from June to November, to a resting phase between December and May (Piazzi \& Cinelli 1999, Ruitton et al. 2005a). In particular, at our study site, at depths ranging from 3 to $6 \mathrm{~m}$, C. racemosa disappears from November to March, to grow back in early spring and peak in abundance in August and September.

Experimental design. In order to test hypotheses from alternative models, patterns of invasion were compared between different algal assemblages (algal turfs versus barrens) and between natural assemblages and their mimics, in different conditions of sediment deposition and grazing pressure. In May 2006, 12 barren patches with a size ranging from 30 to $40 \mathrm{~m}^{2}$, with a slope less than $10^{\circ}$ and separated by tens of metres, were haphazardly chosen among a greater number available. Urchins were removed from 6 randomly chosen patches and were left untouched in those remaining (Fig. 1). Each patch was then randomly assigned to one of the following 3 habitats: (1) barren at natural rates of sediment deposition, (2) barren at enhanced rates of sediment deposition

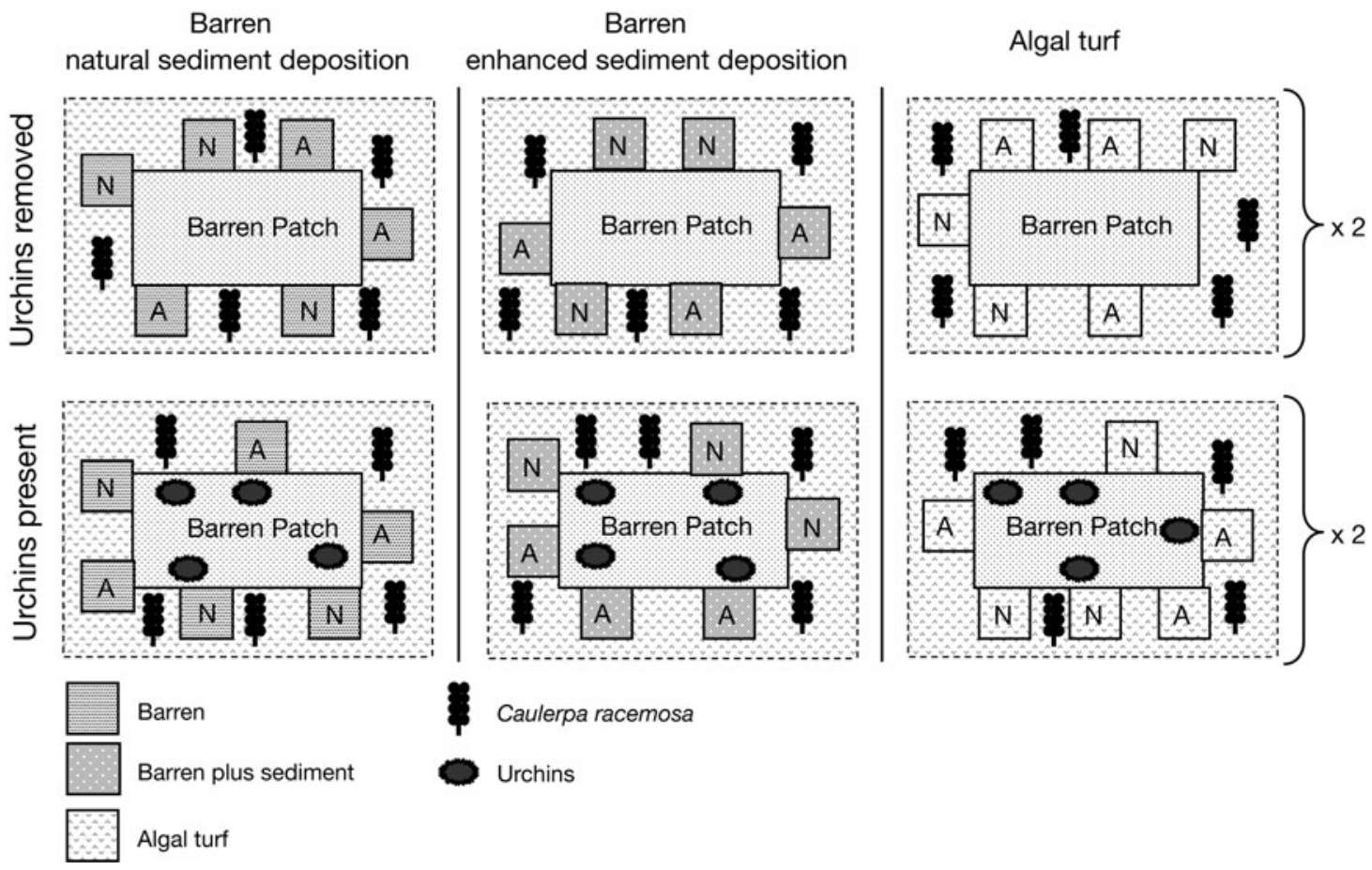

Fig. 1. Experimental design. For each urchin treatment (present vs. removal), 2 patches were assigned to each habitat (barren with natural sediment deposition; barren with enhanced sediment deposition; algal turf); for each patch, 3 quadrats embedded in the surrounding algal turf (colonised by Caulerpa racemosa) were randomly assigned to natural assemblages (N) and 3 to artificial mimics (A) 
and (3) Turf (Fig. 1). Along the perimeter of each patch, six $15 \times 15 \mathrm{~cm}$ quadrats, occupied by algal turfs, were randomly identified, tens of centimetres apart, on horizontal surfaces and marked with epoxy putty at their corners. Three of these were then randomly selected for occupation by natural assemblages, and the remaining three by artificial mimics (Fig. 1). Positioning of quadrats along the margins of patches was necessary to standardise their distance from areas where Caulerpa racemosa had already established (turfs) and from urchin refuges.

Manipulation of herbivores. The 2 species of sea urchins, Arbacia lixula and Paracentrotus lividus, were treated as a guild, since previous studies have documented weak species-specific effects of these grazers on Caulerpa racemosa (F. Bulleri et al. unpubl.). Where necessary, urchins were manually removed at the beginning of the experiment and thereafter at fortnightly intervals. The density of urchins was quantified on 2 occasions (June and July) by recording the number of individuals within 5 randomly placed $50 \times 50 \mathrm{~cm}$ quadrats for each patch. Our procedure was effective at reducing the density of urchins (mean values $\pm \mathrm{SE}=0.03 \pm 0.03$ ind. $0.25 \mathrm{~m}^{-2}$ at both times of sampling; $\mathrm{n}=30$ ), in comparison to control patches (mean values $\pm \mathrm{SE}=4.17 \pm$ 0.77 and $3.47 \pm 0.57$ ind. $0.25 \mathrm{~m}^{-2}$ at the first and second time of sampling, respectively; $\mathrm{n}=30$ ). Two-way ANOVAs, including the factors Herbivore treatment (fixed) and Patch (random and nested within Herbivore treatment) confirmed significant differences between control and removal patches at both times of sampling (Time 1: MS $=256.27, F_{1,10}=14.60, \mathrm{p}<$ 0.01; Time 2: $\mathrm{MS}=23.67, F_{1,10}=48.28, \mathrm{p}<0.001$ ).

Natural and artificial assemblages. Artificial assemblages simulating barren habitats consisted of pale pink PVC panels, $15 \times 15 \times 0.3 \mathrm{~cm}$ in size, whose upper surface was roughened with coarse sandpaper to increase the similarity with local substrata covered by encrusting corallines. Patches of artificial turf (100\% polypropylene), glued onto PVC panels of the same size, were used as a surrogate for algal turfs. This material is considered a good mimic for algal turfs, since it is characterised by a dense mat-like structure, with fronds of similar height, and quickly entraps sediments (Kelaher 2002). Panels mimicking each type of habitat were fixed by means of stainless steel screws plugged into holes drilled in the substratum. Due to their limited thickness $(3 \mathrm{~mm})$, panels were almost flush with the surrounding habitat and their susceptibility to invasion by Caulerpa racemosa was not likely to differ from natural counterparts. In order to standardise among treatments the probability of being invaded by C. racemosa from the surrounding habitat, experimental units (quadrats and panels) had 3 of their
4 sides embedded within the turfing matrix (Fig. 1). Experimental barren quadrats were created by gently removing overlying algal turfs by using a paint scraper and tweezers. Light scraping did not affect encrusting algae (Bulleri 2006) or alter the topography of the substratum, which was, therefore, comparable to that of panels mimicking this type of habitat.

Cover of Caulerpa racemosa around experimental quadrats. The rain of fragments of C. racemosa was assumed to be equally distributed along the stretch of coast studied, but it was necessary to check whether its percentage cover varied in the surroundings of quadrats assigned to natural or artificial assemblages and among patches assigned to different combinations of habitat and herbivore treatments. Before the experiment was started, the percentage cover of C. racemosa around experimental plots was estimated using a photographic sampling. Two photographs were taken haphazardly within a radius of about $50 \mathrm{~cm}$ from the margins of each quadrat using a digital camera (Canon S70) equipped with a waterproof case (Canon WPDC40), a metal distancer and framer, thus ensuring that each photograph covered the same surface of the rocky substrate (a $20 \times 15 \mathrm{~cm}$ rectangle). A grid of 25 subquadrats was then superimposed onto each image (JPEG file) on a PC screen and the percentage cover of C. racemosa in these quadrats was quantified visually giving a score from 0 (absence) to 4 (occupation of the entire quadrat) to each subquadrat and summing over the entire set of subquadrats (Dethier et al. 1993).

Removal of Caulerpa racemosa from quadrats before the start of the experiment. The procedure we used to expose encrusting forms in experimental quadrats (e.g. to generate barren habitats, irrespective of the manipulation of the sediment) ensured the elimination of any C. racemosa present before the start of the experiment. Quadrats occupied by algal turfs were thoroughly searched twice for C. racemosa before the start of the experiment. If present, it was removed manually by using tweezers, in order to minimise damage to other components of algal assemblages. Quadrats were reinspected about 2 wk later, for portions of the alga not previously eliminated. The efficacy of this procedure had been assessed in the framework of a previous study, where the cover of $C$. racemosa in removal quadrats never exceeded $1.5 \%$ when the vegetative encroachment from the margins was prevented (F. Bulleri et al. unpubl.).

Addition of sediment to barren habitats. In May 2006, the spatial variation in the amount of sediment trapped by algal turfs was assessed by destructively sampling portions of horizontal substratum of $10 \times$ $10 \mathrm{~cm}$ in size. In each of 2 areas, 5 quadrats, totally covered by turf and $10 \mathrm{~s}$ of $\mathrm{cm}$ apart, were gently scraped to bare rock and the material collected put in a plastic 
bag and brought to the laboratory. Dispersal of sediment during collection of samples was minimised by delimiting quadrats with a $5 \mathrm{~cm}$ high square frame. The sediment was separated from algal tissues and salts by washing samples with distilled seawater and larger particles entangled in the turfing matrix were removed with tweezers (Airoldi \& Virgilio 1998). Samples were dried to constant weight $\left(60^{\circ} \mathrm{C}\right.$ for $\left.24 \mathrm{~h}\right)$ before weighing on a precision scale (Airoldi \& Virgilio 1998). The weight of the sediment collected from quadrats varied between 28.04 and $4.62 \mathrm{~g}$ in one patch and between 44.56 and $6.35 \mathrm{~g}$ in the other.

At the study site, inputs of sediment to shallow water habitats are mainly due to run-off from the overtopping sandstone cliff during heavy rain episodes. In order to use the same type of sediment as in algal turfs, the material to be added to barren habitats (either natural or artificial) was collected up the cliff. The sediment was passed through a $2 \mathrm{~mm}$ mesh and the fraction not retained, composed of fine particles with a grain size within the range of those trapped by algal turfs (Airoldi \& Virgilio 1998), was used for our manipulation. Added sediment was only partially retained in barren habitats, probably due to the limited depths at which we operated and it was therefore necessary to estimate the rate at which sediments were washed away.

At 5 different times before the start of the experiment, a fixed amount of sediment (30 g) was deposited in five $15 \times 15 \mathrm{~cm}$ quadrats marked on horizontal barren habitats and the amount retained was measured after variable periods of time $(0,2,3,5$ and $7 \mathrm{~d})$. A suction sampler connected to a SCUBA tank was used to collect the sediment from experimental quadrats. The sediment was gently vacuumed from the substratum with a flexible $25 \mathrm{~mm}$ diameter rubber hose mounted on the draft tube and drawn through nylon stockings (Balata et al. 2005). The weight of the sediment was estimated following the same procedures previously described. The proportion of sediment lost as a consequence of manipulative procedures used (i.e. deployment and collection of sediment) was estimated as the difference in weight between the amount deposited (30 g) and that collected after 1 to 2 min from deposition ( $0 \mathrm{~d}$ trial). It was then possible to assess daily rates at which the sediment was washed away from experimental quadrat by currents (on average $3.66 \mathrm{~g} \mathrm{~d}^{-1}$ ) and to calculate the amount to be added in order to raise values to levels matching those found in algal turfs. Natural patterns of variation in the amount of sediment trapped by algal turfs at the scale of tens of metres (between patches) were maintained by random coupling each of the 2 experimental patches assigned to the addition of sediment to the barren habitat (2 patches for each level of the herbivore treatment) to one of the patches from which estimates were previously derived. Likewise, natural patterns of variation at the scale of tens of centimetres (among quadrats) were maintained in barren habitats, as the amount to be deposited in each of the 3 pairs of quadrats (each pair made by 1 natural and 1 artificial unit) was randomly drawn from the 5 replicate measures available for each patch. Building on daily rates of sediment dispersal in barren habitats, we calculated the amount to be deployed in each quadrat every $10 \mathrm{~d}$ to obtain an average equal to the value desired. Due to calm sea conditions, deposition of sediment could be executed at regular intervals and never with a delay greater than 1 to $2 \mathrm{~d}$.

Assessment of the invasion by Caulerpa racemosa. The response of C. racemosa to experimental conditions was evaluated in August 2006, about 45 d after the start of the experiment. By that time, species composing algal turfs had not colonised panels (either mimicking barrens or turfs) or barren habitats. The percentage cover of $C$. racemosa in experimental plots was estimated visually using a $13 \times 13 \mathrm{~cm}$ grid, thus leaving a $2 \mathrm{~cm}$ wide external margin in order to avoid edge effects. The performance of C. racemosa was quantified as the total number of fronds and the length of 3 randomly chosen fronds ( $>2 \mathrm{~mm}$ ) for each quadrat. Finally, the maximum distance from the margins of the quadrat achieved by stolons of $C$. racemosa (hereafter referred to as penetration) was measured in order to assess how our manipulation affected the expansion into new areas.

Response variables were compared among treatments using a mixed-model ANOVA, including the following factors: Urchins (control versus removal; fixed), Habitat (turf versus barren at natural sediment deposition versus barren at enhanced sediment deposition; fixed, crossed with Urchins), Substratum (natural versus artificial; fixed and crossed with Urchins and Habitat) and Patch (random and nested within Urchins and Habitat). The same design was used to assess variation in the percentage cover of Caulerpa racemosa in the surroundings of experimental quadrats before the experiment was started (estimates provided by each pair of photographs taken for each quadrat were averaged). Cochran's $C$-tests were used to test for heterogeneity of variances. When homogeneity of variances could not be achieved by transformation, data were analysed nonetheless, since ANOVA is robust for departure from this assumption when there are many independent replicates and sizes of samples are equal (Underwood 1997). Results were, however, interpreted with caution by judging significance more conservatively $(\alpha=0.01)$. Student-Newman-Keuls (SNK) tests were performed for a posteriori comparisons of the means (Underwood 1997). 


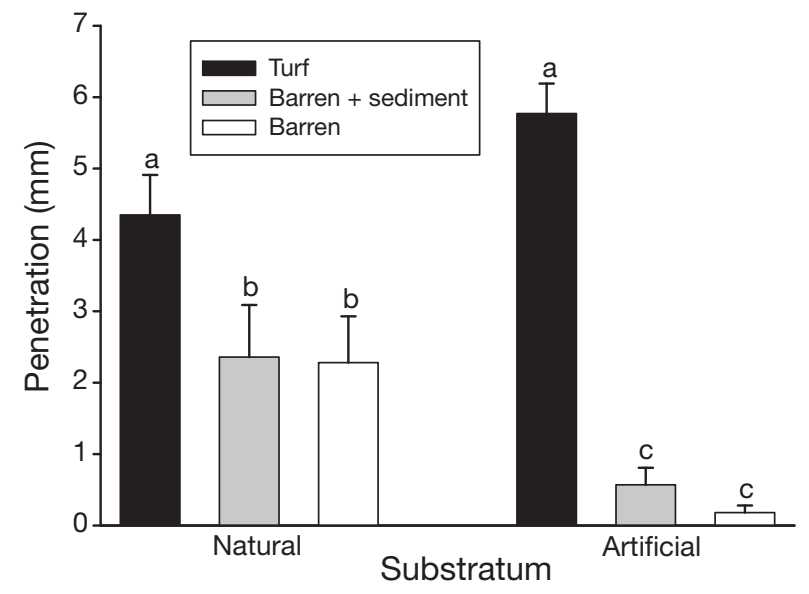

Fig. 3. Caulerpa racemosa. Mean $( \pm \mathrm{SE})$ penetration of stolons into algal turfs, barrens at enhanced deposition of sediment and barren at natural deposition of sediment, separately for natural and artificial substrata $(n=12)$; letters above the columns illustrate the ranking of the means from SNK tests

marked tendency for fronds of $C$. racemosa to be longer in natural $(4.71 \pm 0.80 \mathrm{~mm})$ than in artificial $(2.94 \pm 0.71 \mathrm{~mm})$ substrata (Table 1$)$.

The penetration of stolons of Caulerpa racemosa varied among habitats, but not consistently between natural and artificial substrata (Table 1). Nonetheless, the SNK tests indicated that penetration was greater in algal turfs than in barren habitats, both in natural and artificial substrata (Fig. 3). Significant differences emerged between natural and artificial barren habitats, irrespective of the regime of sediment deposition, but not between natural and artificial algal turfs (Fig. 3).

Herbivores did not affect patterns of distribution or morphological features of Caulerpa racemosa, since the factor Urchins was not significant in the analysis, either as a main effect or as an interaction with other factors (Table 1).

Finally, variability from one patch to another was generally large for all the response variables investigated, except for the penetration of stolons of Caulerpa racemosa (Table 1).

\section{DISCUSSION}

The spread and growth of Caulerpa racemosa was greater in algal turfs than in barren habitats, irrespective of the nature of the substratum, in accordance with previous findings of Ceccherelli et al. (2002). The lack of differences between natural assemblages and their mimics strongly suggests that the nature of positive effects of algal turfs on C. racemosa is physical. Although fundamentally different algal assemblages have been referred to as turfs and there is considerable variation in life-history traits of components in different regions of the world (L. Airoldi \& S. D. Connell pers. comm.), at our study site, algal turfs are generally composed of a relatively high number of tightly packed species that form a complex 3-dimensional matrix (Airoldi et al. 1995). This structure has been reported to be very effective in collecting and trapping debris moving on the bottom, including sediments and, as supposed by Ceccherelli et al. (2002), fragments of C. racemosa. Along with such an effect, algal turfs are likely to provide a safer anchoring of prostrate stolons of C. racemosa, in comparison to lower-complexity habitats such as encrusting coralline-dominated surfaces. Although our study cannot separate the relative contribution of a greater entrapment of current-borne fragments from that of safer anchoring of the stolons to the onset of positive effects of algal turfs on this invader, it has clearly shown that such effects are generated by the intrinsic complexity of this algal assemblage. A descriptive study by Ruitton et al. (2005b) also supports our findings; they indicated that the dead mat of the seagrass Posidonia oceanica is the most favourable substratum for the colonisation of $C$. racemosa in the Mediterranean Sea. This type of habitat is, in fact, characterised by high topographic complexity (Kendrick et al. 2005) and may favour C. racemosa through the same mechanisms we propose for algal turfs.

The present study, documenting a greater success of Caulerpa racemosa in algal turfs than in barren habitats, suggests that the interplay between traits of native species/functional groups and traits of the invader determines overall invasibility. C. racemosa reproduces vegetatively from fragments and its ability to overgrow other sessile organisms, both invertebrates and algae, is not limited by the availability of free space. In contrast, the creation of patches of bare space, maximising the availability of resources such as space and light, was effective at enhancing the biomass of marine invaders characterised by reproductive strategies different from those of C. racemosa (sea squirts in Stachowicz et al. 2002; ephemerals and the canopy-forming alga Fucus serratus in Arenas et al. 2006; Codium fragile ssp. tomentosoides in Bulleri \& Airoldi 2005). On the other hand, in stressful environments, habitat amelioration by resident species has been hypothesised to facilitate colonisation by invaders, eventually generating a positive relationship between diversity and invasibility (Simberloff \& Von Holle 1999, Bruno et al. 2003, Bulleri \& Airoldi 2005, Bulleri et al. 2008). Since a wide spectrum of resources is necessary for plants to grow and reproduce, the benefits for invaders generated by the increased supply in a subset of these, following the loss of components of 
native assemblages, may be counterbalanced or overwhelmed by the deprivation of facilitative effects (Bulleri et al. 2008). Here, pre-emption of space by turfs does not seem to monopolise resources at the expense of the specific invader under investigation, but rather it facilitates its persistence and growth by providing a suitable substratum for its establishment.

A simple plastic reproduction of the 3-dimensional turfing matrix was enough to induce the same effects on all the variables that were used to estimate the abundance and performance of Caulerpa racemosa. Nonetheless, stating that the invasion success of $C$. racemosa might be predicted from habitat complexity would be overly simplistic. Intact seagrass beds are resistant to invasion by the congeneric C. taxifolia, despite the intricacy of rhizomes providing a potentially suitable surface for the attachment of stolons (Ceccherelli \& Cinelli 1999). Similarly, C. racemosa is not able to invade remnant stands of the canopy-forming species Halopitis incurvus and Cystoseira spp. (F. Bulleri unpubl. data), enforcing the model that tradeoffs between availability of resources and facilitation govern invasibility (Bulleri et al. 2008). When strong competitors (seagrasses or canopy-forming algae) come to dominate assemblages, the importance of negative effects due to depletion of limiting resources (space and light) or through physical interference (e.g. sweeping of the substratum) would, therefore, override facilitative effects generated by the provision of a complex substratum.

Although they did not influence patterns among habitats, there were differences between natural and artificial assemblages in the penetration of stolons and length of fronds of Caulerpa racemosa. The penetration of stolons was greater in natural than artificial barren habitats, irrespective of the regime of sediment deposition, but did not differ between natural and artificial turfs. Roughening of PVC panels with sandpaper before deployment may not have adequately reproduced (or increased) the complexity and heterogeneity of the surface of encrusting corallines, lessening the ability of stolons to gain a firm hold on the substratum. A parallel study carried out in the same location has documented a greater penetration of C. racemosa stolons in areas dominated by encrusting corallines than on bare rock surfaces, suggesting that living corallines, being characterised by pits and ridges, may facilitate to some extent the hold of stolons (F. Bulleri et al. unpubl.). Likewise, longer fronds were found in natural than in artificial assemblages, but these differences were consistent among habitats. In this case, differences in frond length between natural and artificial assemblages is unlikely to be the result of an eventual mismatch in their relative complexities, but rather suggests that the presence of living organisms was some- how efficient at enhancing the performance of this species. Differences may have been generated by variation in the biological history between natural assemblages and artificial mimics; when the experiment was started, panels had not been previously exposed to the marine biota, and colonisation by C. racemosa may have proceeded only after the establishment of a biofilm (F. Bulleri pers. obs.), resulting in shorter fronds in comparison to natural assemblages by the end of the study.

Raising the amount of sediments in barren habitats to levels found in algal turfs did not affect the colonisation and performance of Caulerpa racemosa. A persisting layer of sediments on experimental barren habitat plots was therefore not effective at trapping fragments of the alga or at enhancing their anchoring to the substratum by providing more favourable hydrodynamic conditions. These results suggest that the positive relationship between C. racemosa and sediment loads (Piazzi et al. 2007) is likely to be generated by the capability of the complex network of stolons of the alga to entrap particles. Associated changes to macroalgal assemblages rather than increased rates of sedimentation per se could therefore be identified as the primary cause of the spread of C. racemosa along the northwest coast of Italy. Enhanced loads of sediment to coastal habitats, along with water eutrophication, have been indicated as the main determinants of the shift of dominance from canopy-forming species to algal turfs (Airoldi et al. 1995, Benedetti-Cecchi et al. 2001, Gorgula \& Connell 2004). Once established, algal turfs, while hindering the recovery of more diverse algal assemblages through pre-emption of space and retention of sediments (Bulleri et al. 2002, Airoldi 2003), facilitate the spread of $C$. racemosa through the provision of a more suitable substratum. Indeed, when established within algal turfs, C. racemosa would exacerbate negative effects on native assemblages by fostering entrapment of sediments (Piazzi et al. 2007).

The urchins Paracentrotus lividus and Arbacia lixula did not influence any of the response variables used to assess the response of Caulerpa racemosa to the manipulative conditions, suggesting that consumption of C. racemosa by these herbivores was rather small regardless of the type of habitat. These results contrast with a study that documented positive effects of these species of urchins on the ability of the stolons of the alga to penetrate into experimental quadrats (F. Bulleri et al. unpubl.). Since C. racemosa is palatable to urchins (Ruitton et al. 2006), positive effects were interpreted as the outcome of trade-offs between consumption and enhancement in the supply of nitrogen (mostly ammonia) through their excretions (F. Bulleri et al. unpubl.). In the present study, lack of important effects of herbivores may be simply because the time 
over which the effects of our manipulation on the colonisation of $C$. racemosa were estimated was too short for herbivores to influence the invader. Alternatively, it could reflect the large temporal variability in the effects of grazing by these species of urchins (Benedetti-Cecchi et al. 1998, Bulleri et al. 1999).

In conclusion, this study has shown that the nature of the mechanisms underlying the facilitation of Caulerpa racemosa by algal turfs is physical. On the one hand, these findings have important practical implications for the management of this species, enhancing our ability to predict locales more susceptible to invasion. Unfortunately, canopy-forming species are progressively replaced by turf-forming assemblages along urban and sub-urban traits of coasts (Airoldi et al. 1995, Benedetti-Cecchi et al. 2001, Airoldi 2003) and allow us to predict a further spread of C. racemosa. On the other hand, the results of the present study suggest that current invasion theories, based on the assumption that interactions between native and exotic species are exclusively negative, may be inadequate (Bulleri et al. 2008). Although facilitation is perceived to play a marginal role in structuring assemblages of organisms, recent work has suggested that the shape of the relationship between native and exotic diversity could change according to the availability of resources and the intervention of facilitative effects (Stachowicz \& Byrnes 2006, Bulleri et al. 2008). The present study enforces that view and could contribute to the explaining of discordant effects of biodiversity on invasibility mostly documented in terrestrial systems, such as grasslands, agricultural fields and forests.

Acknowledgements. We sincerely thank T. Alestra and L. Tamburello for valuable help in the field. L. Airoldi, F. Arenas, D. Balata, I. Bertocci, M. A. Davis and 3 anonymous reviewers provided insightful comments on earlier versions of the manuscript. This is publication number MPS-08034 of the MARBEF Network of Excellence.

\section{LITERATURE CITED}

Airoldi L (2003) The effects of sedimentation on rocky coast assemblages. Oceanogr Mar Biol Annu Rev 41:161-236

> Airoldi L, Virgilio M (1998) Responses of turf-forming algae to spatial variations in the deposition of sediments. Mar Ecol Prog Ser 165:271-282

Airoldi L, Rindi F, Cinelli F (1995) Structure, seasonal dynamics and reproductive phenology of a filamentous turf assemblage on a sediment influenced, rocky subtidal shore. Bot Mar 38:227-237

Airoldi L, Fabiano M, Cinelli F (1996) Sediment deposition and movement over a turf assemblage in a shallow rocky coastal area of the Ligurian Sea. Mar Ecol Prog Ser 133: 241-251

Arenas F, Sánchez I, Hawkins SJ, Jenkins SR (2006) The invasibility of marine algal assemblages: role of functional diversity and identity. Ecology 87:2851-2861
Argyrou M, Demetropoulos A, Hadjichristophorou M (1999) Expansion of the macroalga Caulerpa racemosa and changes in softbottom macrofaunal assemblages in Moni Bay, Cyprus. Oceanol Acta 22:517-528

Balata D, Piazzi L, Cecchi E, Cinelli F (2005) Variability of Mediterranean coralligenous assemblages subject to local variation in sediment deposition. Mar Environ Res 60: 403-421

Benedetti-Cecchi L, Bulleri F, Cinelli F (1998) Density dependent foraging of sea urchins in shallow subtidal reefs on the west coast of Italy (western Mediterranean). Mar Ecol Prog Ser 163:203-211

Benedetti-Cecchi L, Pannacciulli F, Bulleri F, Moschella PS, Airoldi L, Relini G, Cinelli F (2001) Predicting the consequences of anthropogenic disturbance: large-scale effects of loss of canopy algae on rocky shores. Mar Ecol Prog Ser 214:137-150

> Bertness MD, Callaway RM (1994) Positive interactions in communities. Trends Ecol Evol 9:191-193

Bruno JF, Stachowicz JJ, Bertness MD (2003) Inclusion of facilitation into ecological theory. Trends Ecol Evol 18: $119-125$

> Bulleri F (2006) Duration of overgrowth affects survival of encrusting coralline algae. Mar Ecol Prog Ser 321:79-85

> Bulleri F, Airoldi L (2005) Artificial marine structures facilitate the spread of a non-indigenous green alga, Codium fragile ssp. tomentosoides, in the north Adriatic Sea. J Appl Ecol 42:1063-1072

Bulleri F, Benedetti-Cecchi L, Cinelli F (1999) Grazing by the sea urchins Arbacia lixula L. and Paracentrotus lividus Lam. in the Northwest Mediterranean. J Exp Mar Biol Ecol 241:81-95

Bulleri F, Benedetti-Cecchi L, Acunto S, Cinelli F, Hawkins SJ (2002) The influence of canopy algae on vertical patterns of distribution of low-shore assemblages on rocky coasts in the northwest Mediterranean. J Exp Mar Biol Ecol 267: 89-106

Bulleri F, Bruno JF, Benedetti-Cecchi L (2008) Beyond competition: incorporating positive interactions between species to predict ecosystem invasibility. PLoS Biol 6(6):e162

Callaway RM (1995) Positive interactions among plants. Bot Rev 61:306-349

Ceccherelli G, Cinelli F (1999) Effects of Posidonia oceanica canopy on Caulerpa taxifolia size in a north-western Mediterranean bay. J Exp Mar Biol Ecol 240:19-36

> Ceccherelli G, Piazzi L (2001) Dispersal of Caulerpa racemosa fragments in the Mediterranean: lack of detachment time effect on establishment. Bot Mar 44:209-213

Ceccherelli G, Piazzi L, Balata D (2002) Spread of introduced Caulerpa species in macroalgal habitats. J Exp Mar Biol Ecol 280:1-11

> Dethier MN, Graham ES, Cohen S, Tear LM (1993) Visual versus random-point percent cover estimations: 'objective' is not always better. Mar Ecol Prog Ser 96:93-100

Elton CS (1958) The ecology of invasions by animals and plants. Methuen, London

Fargione JE, Tilman D (2005) Diversity decreases invasion via both sampling and complementarity effects. Ecol Lett 8: 604-611

Friedlander M, Kosov Y, Keret G, Dawes C (2006) Production of rhizoids by Caulerpa prolifera in culture. Aquat Bot 85 : 263-266

> Gorgula SK, Connell SD (2004) Expansive covers of turf-forming algae on human-dominated coast: the relative effects of increasing nutrient and sediment loads. Mar Biol 145: 613-619

Grosholz E (2002) Ecological and evolutionary consequences 
of coastal invasions. Trends Ecol Evol 17:22-27

Kelaher BP (2002) Influence of physical characteristics of coralline turf on associated macrofaunal assemblages. Mar Ecol Prog Ser 232:141-148

Kendrick GA, Marbà N, Duarte CM (2005) Modelling formation of complex topography by the seagrass Posidonia oceanica. Estuar Coast Shelf Sci 65:717-725

Kennedy TA, Naeem S, Howe KM, Knops JMH, Tilman D, Reich P (2002) Biodiversity as a barrier to ecological invasion. Nature 417:636-638

Larned ST (1998) Nitrogen- versus phosphorus-limited growth and sources of nutrients for coral reef macroalgae. Mar Biol 132:409-421

Levin PS, Coyer JA, Petrik R, Good TP (2002) Communitywide effects of nonidigenous species on temperate rocky reefs. Ecology 83:3182-3193

Levine JM, D'Antonio CM (1999) Elton revisited: a review of evidence linking diversity and invasibility. Oikos 87:15-26

Lonsdale WM (1999) Global patterns of plant invasions and the concept of invasibility. Ecology 80:1522-1536

Loreau M (2000) Biodiversity and ecosystem functioning: recent theoretical advances. Oikos 91:3-17

Mack RN, Simberloff D, Lonsdale WM, Evans H, Clout M, Bazzaz FA (2000) Biotic invasions: causes, epidemiology, global consequences, and control. Ecol Appl 10:689-710

Piazzi L, Cinelli F (1999) Development and seasonal dynamics of a population of the tropical alga Caulerpa racemosa (Forsskål) J. Agardh in the Mediterranean. Cryptogam Algol 20:295-300

Piazzi L, Balestri E, Cinelli F (1994) Presence of Caulerpa racemosa in the north-western Mediterranean. Cryptogam Algol 15:183-189

Piazzi L, Ceccherelli G, Cinelli F (2001) Threat to macroalgal diversity: effects of the introduced green alga Caulerpa racemosa in the Mediterranean. Mar Ecol Prog Ser 210:149-159

Editorial responsibility: Laura Airoldi, Ravenna, Italy
Piazzi L, Meinesz A, Verlaque M, Akcali B and others (2005) Invasion of Caulerpa racemosa var. cylindracea (Caulerpales, Chlorophyta) in the Mediterranean Sea: an assessment of the spread. Cryptogam Algol 26:189-202

Piazzi L, Balata D, Foresi L, Cristaudo C, Cinelli F (2007) Sediment as a constituent of Mediterranean benthic communities dominated by Caulerpa racemosa var. cylindracea. Sci Mar 71:129-135

Pimentel D, Lach L, Zuniga R, Morrison D (2000) Environmental and economic costs of nonindigenous species in the United States. Bioscience 50:53-65

Ruitton S, Verlaque M, Boudoresque CF (2005a) Seasonal changes of the introduced Caulerpa racemosa var. cylindracea (Caulerpales, Chlorophyta) at the northwest limit of its Mediterranean range. Aquat Bot 82:55-70

Ruitton S, Javel F, Culioli JM, Meinesz A, Pergent G, Verlaque M (2005b) First assessment of the Caulerpa racemosa (Caulerpales, Chlorophyta) invasion along the French Mediterranean coast. Mar Pollut Bull 50:1061-1068

Ruitton S, Verlaque M, Aubin G, Boudoresque CF (2006) Grazing on Caulerpa racemosa var. cylindracea (Caulerpales, Chlorophyta) in the Mediterranean Sea by herbivorous fishes and sea urchins. Vie Milieu 56:33-41

Simberloff DF, Von Holle B (1999) Positive interactions of nonindigenous species: invasional meltdown? Biol Invasions $1: 21-32$

Stachowicz JJ, Byrnes JE (2006) Species diversity, invasion success, and ecosystem functioning: disentangling the influence of resource competition, facilitation, and extrinsic factors. Mar Ecol Prog Ser 311:251-262

Stachowicz JJ, Fried H, Osman RW, Whitlatch RB (2002) Biodiversity, invasion resistance, and marine ecosystem function: reconciling pattern and process. Ecology 83: $2575-2590$

Underwood AJ (1997) Experiments in ecology: their logical design and interpretation using analysis of variance. Cambridge University Press, Cambridge

Submitted: November 16, 2007; Accepted: March 18, 2008 Proofs received from author(s): July 9, 2008 